\title{
Teacher Professional Development in Research Skill of Teacher in Non-Formal Education Center, Lampang, Thailand
}

\author{
Pongwat Fongkanta ${ }^{1}$, Fisik Sean Buakanok ${ }^{1}$, Ammaret Netasit ${ }^{1} \&$ Suwannee Kruaphung ${ }^{1}$ \\ ${ }^{1}$ Faculty of Education, Lampang Rajabhat University, Thailand \\ Correspondence: Pongwat Fongkanta, Faculty of Education, Lampang Rajabhat University, Thailand.
}

Received: October 31, 2021

Accepted: December 20, 2021

Online Published: December 30, 2021

doi:10.5539/jel.v11n1p125

URL: https://doi.org/10.5539/jel.v11n1p125

\begin{abstract}
The educational policy will be developing strong human competency in which teachers' research skill was one of most competency standards. This study introduces teachers' research skill development through the Wlodkowski's motivational approach and coaching and to study the teachers' attitude toward action research. This study also examines the struggles and problem of doing action research. Participants included 12 teachers who are in the non-formal education center, Lampang, Thailand. The Wlodkowski's motivational approach and coaching were used to develop teachers' research skill. Data was collected by using the research skill inventory (RSI) and the research attitude toward inventory (RATI) which struggle and problems of doing action research questions. Descriptive statistics were used to analyze teachers' research skill and teachers' attitude toward. Friedman test and Wilcoxon test were conducted to evaluate median differences among the reseach skills and created pairwise comparisons. Content analysis was used to analyze the struggles and problem of doing action research. Results revealed that in-service teachers' research skills increased in all domains. Teachers' research skill scores after received treatment were significantly greater than the teachers' research skill scores before received treatment, $\mathrm{z}=-3.07, \mathrm{p}=.002$. The posttest score of teachers' attitudes toward was significantly greater than pretest score, $\mathrm{z}=-3.08, \mathrm{p}=.001$. Teachers struggled with how to conduct research and who could help them.
\end{abstract}

Keywords: teacher professional development, motivational approach, research skill, non-formal education

\section{Introduction}

The challenges of a rapidly changing world are embedded in numerous dimensions of society including the human development system. There is the critical policy on the educational center to look for a route to develop adults' professional competence (Office of the non-formal and informal education, 2018). The non-formal and informal education organization is one of the significant supporting resources to push people to step on lifelong learning. One of the organization's mission statements is to develop a contemporary curriculum, learning model, and educational evaluation. There are promoting the accreditation organization within the process to enhance learner capability with research-based approaches (Office of the non-formal and informal education, 2018).

Lifelong learning has emerged as one of the major challenges for the worldwide knowledge society of the future. People are encouraged to continue learning through their life. Teachers are one of the examples of people who have to continue learning for reskilling and upskilling (TPDI, 2017). One of the ways to foster teacher learning is by providing a professional development program. Professional development can be improving teachers' mastery of knowledge, skills and provide opportunities for teacher to engage in sustaining or implementing new knowledge (Mizell, 2010; Anderson, 2008; Kennedy, 2005).

Why is teacher participation in professional development important? This is a common question raised among teachers and others. Commonly, professional development is one of many types of educational experiences related to teachers' work. People in a wide variety of professions have the same purpose for participating in professional development to learn and apply the new knowledge and skill for improving their performance. Educational researchers have shown the significance of professional development in increasing teacher competence, school leadership, and student achievement. Both teachers and schools are continually expanding their knowledge and skills to enhance the best educational practices (Mizell, 2010). Research skill is one the important skill for teachers. There are advanced skills to finding a solution. A review of studies on research skills of developing researchers has revealed some major research skills that important such as information seeking 
skills, writing skills, methodological skills, and data analytical (Willison \& O'Regan, 2007). There was a range of skills necessary for doing research. To evolve teacher competency, research skill development approaches and coaching were used for the teacher professional development. There was a way to enhance teachers' research skills that teachers should be educated by the specific area expertise, instructional specialist, group and dyadic discussions, teacher reflection, and practical experiences through Wlodkowski's motivational approach (Collet, 2015; Laoreandee, 2013; Wlodkowski, 1997).

Teachers in Non-formal Education Center, Hangchat Center promoted the weak research paradigm and research skills. Teachers lack practicing and coaching correspond with expertise. Even though professional development is common tools for enhancing research skills, there seem to be lack of research evidence into how to combine the motivational approach and coaching as a tool of teacher professional development. In this regard, the researcher would be investigating to account for how Wlodkowski's motivational approach combined with coaching processes based on teacher professional development can enrich the teachers' research skill and attitude.

\section{Literature Review}

\subsection{Teacher Professional Development}

Teacher professional development is defined as a cumulative process that improves teachers in the mastery of knowledge, skills, and competencies effectiveness in raising student capability (National Staff Development Council, 2011; Hassel, 1999; Miller \& Carpenter, 1980). Teacher professional development represents a sustained effort to enhance teacher competencies (Kunter, Klusmann, Baumert, Richter, Voss, \& Hachfeld, 2013) as well as career progression and retention in the profession (Coldwell, 2017). Day (1999) considered teacher professional development to be the process by which teachers, alone or in groups, develop knowledge, competencies, and emotional intelligence that was essential elements for improving professional thinking, planning, and practicing throughout each stage of their teaching life. In order to Guskey (2002), the major goals of the professional development program are comprised of altering teachers' classroom projects, altering teachers' attitudes and beliefs, and improving students' academic outcomes. According to Coldwell (2017) founded that teacher's engagement in professional development impacted them on professional knowledge and improved their practice.

\subsection{Wlodkowski's Motivational Framework}

Motivation to learn is the tendency to find learning activities meaningful and worthwhile and also attempt to gain the knowledge and skills from the activity development (Brophy, 2004). The framework to create common motivation in the learning situation for adult learners includes four motivational conditions that the instructor and the adult learner collaboratively enhance. There were (1) establishing inclusion which creating a learning atmosphere for learners and instructors to feel respected by and connected to one another (2) developing attitude which creating a favorable disposition toward the learning experience through personal relevance and choice (3) enhancing meaning which generating challenging, thoughtful learning experiences that include learners' perspectives and values (4) engendering competence which creating an understanding that learners are effective in learning something they value (Wlodkowski, 1997).

\subsection{Coaching}

Coaching is a significant process that enables learning development and competency improvement. There were flourishing critical thinking and providing the opportunity to accept the new variety of knowledge and skills (Robertson, 2011). The coaching process was starting with the pre-coaching session. The pre-coaching session has collaboratively identified the need and the purpose of development. Next, the coaching session was in the middle of a process that to realize their idea, process, and performance. Finally, the post-coaching session was the summary state to independently discuss and summarize their approach of accomplishment. In addition, Wongyai and Patpon (2019) offered the three main elements of how to coach. There were: (1) engagement, the coach was building trust and rapport with the coachee to encourage supported risk-taking and achieve the goal (2) empowerment, the coach was supported and empowered the coachee in working towards sustained behavior change (3) enliven, the coach was prepared to cheer and commit the coachee mind. These were holistic approaches to reach the need that was collaboratively identified.

\subsection{Teachers' Research Skill}

The essential teachers' skill in the current era was developed. The research skill development (RSD) framework was devised to help educators formulate pedagogies that scaffold learner learning about and through research (Willison \& O'Regan, 2007). Alignment of facets of RSD framework for identifying research skill indicators, 
the research skill assessment consisted of the 6 facets of research (Willison \& O'Regan, 2007). There were six components of research skills involved that comprised learners' knowledge and skill in clarifying and selecting the interesting topic. Learner embarked on research, determining, and clarifying the need for understanding the critical idea of the research topic. Finding and generating educational innovation, learners find information and generate data relevant to the research using appropriate methodologies. Evaluating and reflecting, learners get through research design with proper treatment and reflect on all processes used. Organizing and managing data, learners organize data and manage the research process of individuals and teams. Analyzing and synthesizing data, learner analyzing information and data, and synthesizing new knowledge to produce coherent individual and team understandings. Communicating and applying, learners write or speak and also perform the processes applications of the research. Moreover, they responded to the feedback, cultural and team issues (Willison \& O’Regan, 2007).

\subsection{Attitude Toward}

The construct of attitudes has been broadly defined as the probability that a person will show a specified behavior in a specified situation (Campbell, 1950) in which likes and dislikes an object (Bem, 1970). Interpreting the attitude toward being as a combination between a person resulting affective load will have repercussions on the developed behavior (Ellis, 1989 cited in Wlodkowski, 1999). Relevance leads to what human beings experience as interest, the positive feeling nutrient for a positive attitude toward. When we feel interested, we usually have to make choices to follow that interest in the most meaningful way. Attitude changing can occur when people yield the new belief and attitude will be changed by following the way of belief easily (Kelman, 1967).

\section{Method}

\subsection{Research Design}

This study was carried out by using a quasi-experimental of nonequivalent control group design with one group time-series design (Shadish, Cook, \& Campbell, 2002). Three repeated measured was given to the experimental group as pretest, posttest, and follow up.

\subsection{Participants}

A total of 12 were in-service teachers who worked in the non-formal education center, Hangchat center, Thailand. Of these participants, they had more than 3 years of teaching experience.

\subsection{Measurement}

The current study compiled teachers' responses to two of the inventories that was repeated assessment in three times. Teachers were provided with questions to complete included both open-ended and closed-ended questions.

Research skill. To assess teachers' research skills, teachers completed 18 true-false question of the Research Skill Inventory (RSI). The RSI assesses 6 components of research skills including identifing and developing research topic domain, designing a plan of action and develop intervention tool domain, doing research domain, data collection, analyzing and synthesizing data domain and research conclusion and reporting. The total score was 18 with three points in each domain. The RSI was evaluated the content validity by using a rational inspection by subject matter experts. The measures showed the high index of item objective congruence ranging from .67 to 1 .

Research Attitude Toward. To assess teachers' research attitude toward, teachers completed the Research Attitude Toward Inventory (RATI) self-report on a 5-point scale. The 12-items assess the aspect of attitude toward research methodology understanding, emotion to do research, and the benefits of conducting research. The measures showed high reliability using Cronbach's alpha $(\alpha=.71)$.

Struggles and problems of doing research. Open-ended questions were used to obtain information from teachers' self-report in struggling and problems when they are doing research.

\subsection{Procedure}

Teachers in the Hangchat center were recruited for the study. At the start of the study, teachers completed the RSI and RATI as the pretest. The research skills development session was continuing through the Wlodkowski's motivational approach. The workshop designs were:

1) Setting goal: collaborate with an instructor.

2) Generating challenging and thoughtful learning experiences that include learners' perspectives and values. 
Using brainstorming and encouraging an idea by questions that corresponded with current situations learning, and summarization as strategics for learning.

3) Creating a favorable disposition toward the learning experience through personal relevance and choice with synchronous feedback.

The posttest was conducted at the last session. Teachers were asked to complete the test and questionnaires. During the three procedures of the coaching session, feedback was provided to teachers who struggle in doing research. The final procedure was the follow-up session. Participants were asked to report the research skills, research attitude toward, and struggles and problems of doing research.

\subsection{Data Analysis}

The data was collected from teachers who attended the workshop. Participants responded to the test and questionnaires three times for indicating their research skill, research attitude toward, and struggles and problems of doing research. The data analysis, descriptive statistics were used to report the result and determine differences in the research skill and research attitude toward. Moreover, a Friedman test was conducted to evaluate median differences among the reseach skills and the research attitude toward was tested by the Wilcoxon test. Friedman test is an alternative of nonparametric to repeated-measures ANOVA when normality assumption or assumption of equality of variances is not fulfilled (Kvam \& Vidakociv, 2007). Also, the Wilcoxon test was used to create a pairwise comparisons. Furthermore, the content analysis was used to code and categorize themes of struggles and problems.

\section{Results}

The results are classified follows specific objectives as follows:

\subsection{Research Skill Development}

As can be seen in Table 1, the developing result of research skill disclosed the difference of research skill scores by repeated measured three times. The total research skill scores were dramatically raised in the posttest score over to 15.25 with the mean difference from the pretest equal 3.58. However, the teacher's research skill gradually decreased in the follow-up test to 14.75 that a small score decreased from the posttest equal 0.05 .

Table 1. Mean, mean difference, and standard deviation of teachers' research skill

\begin{tabular}{lllllllll}
\hline Research skill domain & Pretest & \multicolumn{3}{c}{ Posttest } & \multicolumn{3}{c}{ Follow up } & \multicolumn{2}{c}{ Mean difference } \\
\cline { 2 - 9 } & Mean & SD & Mean & SD & Mean & SD & Pre: Post & Post: Follow-up \\
\hline 1. Identify and develop research topic & 1.92 & 0.67 & 2.58 & 0.51 & 2.50 & 0.67 & +0.66 & -0.08 \\
2. Design plan of action and develop & 1.67 & 0.49 & 2.67 & 0.49 & 2.33 & 0.49 & +1.00 & -0.34 \\
intervention tool & & & & & & & & \\
3. Do research & 2.00 & 0.74 & 2.50 & 0.67 & 2.42 & 0.79 & +0.50 & -0.08 \\
4. Data collection & 2.08 & 0.79 & 2.67 & 0.49 & 2.58 & 0.67 & +0.59 & -0.09 \\
5. Data analysis & 1.92 & 0.90 & 2.42 & 0.90 & 2.42 & 0.51 & +0.50 & +0.00 \\
6. Research conclusion and reporting & 2.08 & 0.79 & 2.42 & 0.79 & 2.50 & 0.80 & +0.34 & +0.08 \\
Total & 11.67 & 0.16 & 15.25 & 0.11 & 14.75 & 0.09 & +3.58 & -0.50 \\
\hline
\end{tabular}

A Friedman test showed that there was significant difference between teachers' research skill scores measured three times as before received treatment, after received treatmen, and after a month follow up, $\chi^{2}(2,12)=16.84$, $\mathrm{p}<.000$ (Table 2). A pairwise comparisons using Wilcoxon test revealed that the teachers' research skill posttest scores $(\mathrm{Mdn}=15.00)$ were significantly greater than the teachers' research skill pretest scores $(\mathrm{Mdn}=11.50), \mathrm{z}$ $=-3.07, \mathrm{p}=.002$. Also, the teachers' research skill follow-up scores $(\mathrm{Mdn}=15.00)$ were not significantly greater than the teachers' research skill scores after received treatment $(\mathrm{Mdn}=14.50), \mathrm{z}=-.93, \mathrm{p}=.353$ (Table 3).

Table 2. The Friedman Test of three times measurement in teachers' research skill

\begin{tabular}{llll}
\hline Teachers' research skill & Median & Chi-square & p-value \\
\hline Pretest & 11.50 & 16.84 & .000 \\
Posttest & 15.00 & & \\
Follow-up & 14.50 & & \\
\hline
\end{tabular}


Table 3. A pairwise comparisons using Wilcoxon test in teachers' research skill

\begin{tabular}{lll}
\hline Teachers' research skill & $\mathbf{z}$ & $\boldsymbol{p}$-value \\
\hline Pretest-Posttest & -3.07 & .002 \\
Posttest-Follow-up & -.93 & .353 \\
\hline
\end{tabular}

\subsection{Research Attitude Toward}

The three aspects of attitude toward consisted of research methodology understanding, emotional to doing research, and the benefits of conducting research. These domains were assessed. The result revealed that three aspects of attitude toward were dramatically increased in the posttest that measures at the end of the workshop. In order to the highest score was in the research methodology understanding domain $(\mathrm{M}=4.44)$ with highly mean difference (Table 4).

Table 4. Mean, mean difference, and standard deviation of teachers' research attitude toward

\begin{tabular}{llllll}
\hline \multirow{2}{*}{ Research attitude toward domain } & Pretest & & Posttest & & Mean difference \\
\cline { 2 - 5 } & Mean & SD & Mean & SD & Pre: Post \\
\hline 1. Research methodology understanding & 3.54 & .26 & 4.44 & .26 & +.90 \\
2. Emotional to doing research & 3.77 & .29 & 4.42 & .25 & +.65 \\
3. Benefits of conducting research & 3.67 & .36 & 4.40 & .31 & +.73 \\
Total & 3.66 & .30 & 4.42 & .27 & +.76 \\
\hline
\end{tabular}

A comparisons teachers' research attitude toward by using Wilcoxon test. The result revealed that the posttest scores of teachers' research skill $(\mathrm{Mdn}=4.46)$ was significantly greater than the pretest scores of research attitude toward $(\mathrm{Mdn}=3.71), \mathrm{z}=-3.08, \mathrm{p}=.001$ (Table 5).

Table 5. A pairwise comparisons using Wilcoxon test in teachers' research attitude toward

\begin{tabular}{llll}
\hline Teachers' research attitude toward & Median & $\mathbf{z}$ & $\boldsymbol{p}$-value \\
\hline Pretest & 3.71 & -3.08 & .001 \\
Posttest & 4.46 & & \\
\hline
\end{tabular}

\subsection{Struggling and Problem of Doing Research}

The opened-ended questions highlight that teacher experienced problems with the lack of research knowledge program supporting. They perceived the lack of content of research knowledge and lack of confidence in doing research. Teachers often did not know how to conduct the research in the right way. Teacher reflected that "I do research with my understanding, but I do not know I do correctly or not", "I have no time to do, and I am feeling exhausted in my routine work". Furthermore, they asked to be supported by supervisor.

\section{Conclusion and Discussions}

The total research skill scores in all domains were raised and teachers' research skill scores after received treatment were significantly greater than the teachers' research skill scores before received treatment. These results showed that the teachers' research skills were progressing after the training by Wlodkowski's motivational approach and coaching. Teachers gained new knowledge and new skills in doing research. Teachers' research skill scores after received treatment greater the scores before received treatment that presented a high progress of their research skill. Teachers' research skill scores after a month follow-up also remain a high score that showed teachers progression. Also, the findings provide a supporting argument that the teacher development workshop was designed based on the Wlodkowski's framework combined with coaching. As Ginsberg (2001) claimed that the collaboration of teacher development and coaching could support the need for human development. Furthermore, this study also supports a multiple case study that was carried out among students and teachers in school. Results showed the workshop procedure created based on a motivational approach could enhance the research skill (Junpeng, 2011) and teacher gained high research skill and completed their research when the school provided a coach for suggesting the direction of doing research (Hemsiri et al., 2016). Furthermore, executive coaching is effective in increasing teacher performance (McGovern et al., 2001). Therefore, one of the benefits of participating in the training was the effectiveness of developing teacher skills (Andabai, 2013) 
Consider the teachers' research skill scores after a month follow-up, results appeared that the teacher skills were slightly decreased in all domains, however, it was not significant declining their skills. This was highlighting a need for teacher educational workshops to focus more explicitly on their development. As Woodcock and Reupert (2011) presented that the training courses increased teacher efficacy levels. The present study suggested that the research promoting the high academic ranking was reported the highest level of research attitude toward. Teachers needed professional growth and perceived the value of research training for career outcomes. Also, three aspects of attitude toward were at a high level. The teacher development workshop was designed based on the Wlodkowski's framework combined with coaching could enhance their own attitude toward. Due to teacher perceived the value of doing research, there was able to enhance attitude toward. The end of teacher training exhibited the struggles and problem of doing research. Opened-ended questions revealed the interesting finding of the struggles and problem of doing research. These teachers struggled with research methodology. Furthermore, they did not know how they could learn about doing research in another way as well.

For implication, the result of this study could effort the guideline for teacher professional development in research skill. The result showed that workshop activities based on Wlodkowski's framework combined with coaching could raise teacher research skills. This workshop may apply to teacher in another non-formal education center and teachers who look for professional development in research skills. To extend our understanding of how the workshop model can enhance teacher research skills, in future research, researcher should look for the new strategy combination by using technology for encouraging the engagement in professional development. Also, researcher will include a professional learning community for their collaboration in the development program.

\section{References}

Andabai, P. W. (2013). The impact of teaching practice on trainee teachers in the Nigerian Tertiary Institutions: The Niger Delta University Experience. Academic Journal of Interdisciplinary Studies, 2(5), 109. https://doi.org/10.5901/ajis.2013.v2n5p109

Anderson, J. (2008). Teachers' motivation to attend voluntary professional development in K-10 mathematics (pp. 51-58). In The 31st Annual Conference of the Mathematics Education Research Group of Australasia.

Bem, D. J. (1970). Beliefs, attitudes, and human affairs. Belmont, CA: Brooks/Cole.

Brophy, J. E. (2004). Motivating students to learn (2nd ed.). Mahwah, NJ: Erlbaum. https://doi.org/10.4324/9781410610218

Campbell, D. T. (1950). The indirect assessment of social attitudes. Psychological Bulletin, 47, 15-38. https://doi.org/10.1037/h0054114

Coldwell, M. (2017). Exploring the influence of professional development on teacher careers: A path model approach. Teaching and Teacher Education, 61, 189-198. https://doi.org/10.1016/j.tate.2016.10.015

Collet, V. S. (2015). The gradual increase of responsibility model for coaching teachers: Scaffolds for change. International Journal of Mentoring and Coaching in Education, 4(4), 269-292. https://doi.org/10.1108/IJMCE-06-2015-0017

Day, C. (1999). Developing teachers: The challenges of lifelong learning. London: Falmer Press.

Ginsberg, M. B. (2001). By the Numbers. Journal of Staff Development, 22(2), 44-47.

Guskey, T. R. (2002). Professional development and teacher change. Teachers and Teaching: Theory and Practice, 8(3), 381-391. https://doi.org/10.1080/135406002100000512

Hassel, B. C. (1999). The charter school challenge: Avoiding the pitfalls, fulfilling the promise. Washington, DC: The Brookings Institution.

Hemsiri, P., Boonyapithak, S., Wannasuthi, N., \& Yingwanna, S. (2016). A Causal Relationship of research skills of teachers at senior professional level under the songkhla primary education Service area office 3. The 7th Hatyai National and International Conference, Hatyai University, Thailand.

Junpeng, P. (2011). Research-based learning for developing the students' knowledge and research skill, faculty of Education, Khon Kaen University. KKU Research Journal, 1(2), 21-44.

Kelman, C. H. (1967). Basic psychology. New York: Appleton Century Grofts company.

Kennedy, M. M. (2005). Inside teaching: How classroom life undermines reform. Cambridge, MA: Harvard University Press. https://doi.org/10.4159/9780674039513 
Kunter, M., Klusmann, U., Baumert, J., Richter, D., Voss, T., \& Hachfeld, A. (2013). Professional competence of teachers: Effects on instructional quality and student development. Journal of Educational Psychology, 105(3), 805-820. https://doi.org/10.1037/a0032583

Kvam, H. P., \& Vidakociv, B. (2007). Nonparametric statistics with applications to science and engineering. John Wiley and Sons. https://doi.org/10.1002/9780470168707

Laowreandee, W. (2013). Science of teaching supervision and coaching: professional development: theory, strategy to practice. Nakorn Prathom: Silpakorn University printinghouse sanamchan campus.

McGovern, J., Lindemann, M., Vergara, M., Murphy, S., Barker, L., \& Warrenfeltz, R. (2001). Maximising the impact of executive coaching behaviour change, organization outcomes and return on investment. The Manchester Review, 6(1).

Miller, T. K., \& Carpenter, D. S. (1980). Professional preparation for today and tomorrow. In D. G. Creamer (Ed.), Student development in higher education: Theories, practices and future directions (pp. 181-204). Washington, DC: American College Personnel Association.

Mizell, H. (2010). Why professional development matters. Learning Forward (NJ), 1-28. Retrieved from http://www.eric.ed.gov/ERICWebPortal/search/detailmini.jsp?_nfpb=true\&_\&ERICExtSearch_SearchValu e_0 $=$ ED256009\&ERICExtSearch_SearchType_0=no\&accno=ED256009

National Staff Development Council. (2011). Standard for professional learning: Quick reference guide. Retrieved from https://learningforward.org/docs/defaultsource/pdf/standardsreferenceguide.pdf?sfvrsn=0

Office of the non-formal and informal education. (2018). Performance fiscal report 2018. Retrieved from http://www.nfe.go.th/onie2019/index.php/about-us/performance-report.ht

Robertson, J. (2011). Coaching educational leadership: Building leadership capacity through partnership (pp. 6-7). In the 2nd Australian Leadership Coaching Conference for Educators. Melbourne, Australia.

Shadish, W. R., Cook, T. D., \& Campbell, D. T. (2002). Experimental and quasi-experimental designs for generalized causal inference. Boston: Houghton Mifflin.

Teacher Professional Development Institute (TPDI). (2017). Teacher professional development in Thailand. Retrieved from http://www.kurupatana.ac.th/index.html

Willison, J., \& O'Regan, K. (2007). Commonly known, commonly not known, totally unknown: A framework for students becoming researchers. Higher Education Research and Development, 26(4), 393-409. https://doi.org/10.1080/07294360701658609

Wlodkowski, R. J. (1997). Motivation with a mission: Understanding motivation and culture in workshop design. In J. Fleming (Ed.), An update on designing and implementing workshops. New Directions for Adult and Continuing Education, San Francisco, CA: Jossey-Bass

Wlodkowski, R. J. (1999). Enhancing adult motivation to learn: A comprehensive guide for teaching all adults. San Francisco: Jossey-Bass. https://doi.org/10.1002/ace.7602

Wongyai, W., \& Patpon, M. (2019). Coaching for student competency developing. Bangkok: Charansanitwong Printing Co., Ltd.

Woodcock, S., \& Reupert, A. (2011). A Cross-sectional study of student teachers' behaviour management strategies throughout their training years. Australian Educational Researcher. https://doi.org/10.1007/s13384-012-0056-x

\section{Copyrights}

Copyright for this article is retained by the author, with first publication rights granted to the journal.

This is an open-access article distributed under the terms and conditions of the Creative Commons Attribution license (http://creativecommons.org/licenses/by/4.0/). 